\title{
Valved Dispensing Plastic Container Closure
}

National Cancer Institute

\section{Source}

National Cancer Institute. Valved Dispensing Plastic Container Closure. NCI Thesaurus.

Code C96138.

Dispensing closure incorporating a product-flow controlling valve within the orifice.

Product will not dispense from the package until sufficient squeezing pressure is applied to the flexible container to cause the valve to open. 